\title{
SOBRE LA IDEA DE MEDIO AMBIENTE PERCEPTIBLE EN EL TRATADO POR EL QUE SE ESTABLECE UNA CONSTITUCIÓN PARA EUROPA ${ }^{1}$
}

\author{
POR \\ MANUEL JOSÉ TEROL BECERRA \\ Catedrático de Derecho Constitucional \\ Universidad Pablo de Olavide
}

(Sevilla)

\section{INTRODUCCIÓN}

Hace tiempo que se asiste en el terreno doctrinal a la aspiración de construir una disciplina jurídica nueva, el Derecho del medio ambiente o Derecho medioambiental, y que en ese contexto se inscriben no pocas propuestas, de tantos autores, tendentes a conceptuar el medio ambiente identificándolo con la naturaleza o, más exactamente, con los elementos que seguramente la conforman - discutiendo los seguidores de esta corriente mayoritaria si, de acuerdo con ello, basta con el aire y el agua para componer la noción de medio ambiente, o debe entrar además el suelo en su definición-y las formulaciones teóricas de

1 Una versión más antigua de este trabajo - referida al Proyecto de Tratado por el que se instituye una Constitución para Europa, adoptado por consenso por la Comisión Europea los días 13 de junio y 10 de julio de 2003, presentado al Presidente del Consejo Europeo en Roma, y publicado el 18 de julio de 2003- verá la luz en el libro homenaje al Profesor Gumersindo Trujillo que lleva algún tiempo preparándose. 
quienes, sin cuestionar esa identificación entre la naturaleza y el medio ambiente, entienden que éste también apela a otros elementos de carácter económico, social y cultural. Para, a la postre, ofrecer unas y otras tendencias doctrinales una mera enumeración de bienes, más o menos extensa, con la que hacen coincidir su noción de medio ambiente. Operando así con una simple lista, respecto de la cual siempre podría discutirse el criterio utilizado para elaborarla; y sin que ese catálogo sea impermeable a la influencia de lo contingente, como así demuestra la experiencia que, además, sucede en este campo. Lo que no se juzga un criterio sólido con el que proceder a esa delimitación de lo medioambiental. Se sabe que las personas de principios del siglo XXI quieren proteger de lo que les rodea las cosas que les son más queridas, claro está, como la flora, la fauna, y el paisaje, aun cuando su flora, su fauna y su paisaje, sería más correcto decir, cualquiera que sea el estado en que se encuentren no interfiera lo más mínimo en la salud ni en la vida humana. Pero no se sabe que querrán proteger los humanos dentro de cincuenta o cien años. De ahí el intento de aproximarse en estas páginas a una idea de medio ambiente por otra vía. En concreto, por la que sugiere el Tratado por el que se establece una Constitución para Europa en su Art. III-233.2:

"La política medioambiental de la Unión tendrá como objetivo un nivel elevado de protección, teniendo presente la diversidad de situaciones existentes en las distintas regiones de la Unión. Se basará en los principios de precaución y de acción preventiva, en el principio de corrección de los daños al medio ambiente, preferentemente en el origen y en el principio de quien contamina paga».

El propósito es indagar sobre las posibilidades de construir con la ayuda de contaminar una concepto de medio ambiente sustentado en la relación que cabe establecer entre una cosa y los agentes que pueden dañar su naturaleza, cualesquiera que sean aquella y éstos. Pues, en efecto, han sido las escasas consideraciones que el Tratado por el que se establece una Constitución para Europa destina a identificar las cosas protegibles en lo medioambiental, su referencia a contaminar, y su obstinado silencio sobre qué ha de entenderse por tal, las razones que han movido a reflexionar en el sentido indicado.

Responden estas páginas, en definitiva, al objetivo principal de fundamentar la tesis en cuya virtud la idea de medio ambiente formulada en el Tratado por el que se establece una Constitución para Europa sólo es aprehensible gracias a contaminar. Dicho sea en otros términos, se entiende aquí que de la contaminación, o, más exactamente, del propósito dirigido a erradicarla, esto es, del interés por su ausencia, procede el motivo inspirador de la regulación que al medio ambiente le de- 
dica el Tratado. En donde esa precisa circunstancia resulta ser el objetivo de su normación medioambiental. De modo que cuanto concierne a contaminar impregna por entero el tratamiento que allí recibe el medio ambiente, hasta el extremo de concluir revelándose aquella cuestión, en relación con este último, elemento definitorio del concepto de medio ambiente que admite entenderse enuncia el Tratado, cualquiera que sea la óptica, lingüística, sociológica, técnica o incluso jurídica desde la cual se observe su normación de lo medioambiental. Pero conviene obrar con orden.

\section{INDAGACIÓN DIACRÓNICA EN TORNO AL TÉRMINO CONTAMINAR}

\subsection{De sus primeros significados}

Acerca de la información que sigue conviene tener presente su carácter subordinado al servicio de la interpretación jurídica. Pues, sin duda que juzgará el filólogo incompleta la indagación semasiológica que la sustenta, caprichoso el punto de partida y aun el salto en el tiempo que media entre la primera obra consultada y las siguientes. Siempre diccionarios. Casi todos de la Real Academia. Excuse tal proceder si puede el lingüista insatisfecho. Acepte como disculpa que al jurista apenas le importa conocer la significación usual de las palabras empleadas por la norma. A cuyo propósito es patente de cuanta utilidad le será enterarse de posibles significados pretéritos del vocablo por el que se interese.

De encontrarlos podrá formarse con ellos un juicio sobre el significado presente de la palabra con que la norma se exprese. Una opinión que a fuer de fundada en la acepción más moderna del término, lejos de ignorar comprenda el sentido que el vocablo representa para la sociedad de su tiempo. Conviene subrayarlo, pues, provisto de tal información podrá el jurista abordar la interpretación gramatical de la norma y todavía arriesgar una interpretación sociológica de la misma, esto es, tendente a incorporar la realidad en ella, siquiera sea de forma provisional porque conozca como enriquecerla con más datos de esa índole. Dicho sea sin perjuicio de lo que haya de perfilar luego esos juicios, gramatical y sociológico, ya jurídicos con ayuda de las restantes técnicas de interpretación usualmente empleadas en Derecho.

Sopese el jurista avisado si al objeto de conocer la evolución de un término y hacerse con la información señalada asumiría por método la sencilla fórmula de consultar, como aquí se ha hecho, las sucesivas edi- 
ciones del Diccionario de la Real Academia. Luego, eso sí, de hacer lo propio con otro compuesto antes incluso de crearse dicha institución, por el prurito de citar, como antecedente, una fuente más antigua de ese género, ciertamente significada y a la mano en tantas bibliotecas. Diga, en fin, el jurista experimentado si, a la vista de las conclusiones que a continuación se ofrecen, la búsqueda ha sido o no provechosa. Sobre contaminar y sus derivados versa, no se olvide.

De ello trata el Tesoro de la Lengua Castellana o Española². En donde su autor le atribuye a contaminar el significado de "manchar, dañar secretamente y sin que se eche de ver". Al tiempo que a contaminado, su participio pasivo, el de "manchado, dañado, corrompido, ensuciado". Matizando con esto último Sebastián de Covarrubias las consecuencias funestas que, en secreto, puede acarrearle contaminar a cualquier objeto. Toda vez que, sin negar sus eventuales concreciones para éste, en forma de mancha, suciedad o daño, admite que se manifiesten mas seriamente y lleguen al extremo de corromperle.

\section{El Diccionario de autoridades}

Ocioso es buscar más datos sobre la familia léxica considerada en el Tesoro de la Lengua Castellana o Española. Pero, precisamente por eso, porque su información al respecto es poca, sorprende comprobar la notable influencia que ejerció la misma en el primer Diccionario de la Real Academia, el de Autoridades, que, no en balde, la asumió sin dejar además de enriquecerla. Quiere decirse con ello que dicho Diccionario acogió los términos que ya Covarrubias consignara en el suyo, completó tan exiguo catálogo con otros omitidos en aquél, y todavía concedió a sus respectivos significados un mismo tipo de tratamiento, caracterizado por las siguientes notas: la preocupación por ofrecer, como el de Covarrubias, la etimología de las palabras; el respaldo de sus correspondientes definiciones con el rigor erudito de una cita literaria de autoridad, con el consiguiente beneficio enriquecedor para los vocablos ya conocidos, contaminado y contaminar, que conservaron los significados que obtuvieron en el Tesoro de la Lengua Castellana o Española; y una vocación por la exhaustividad que aprovecharía también a contaminar, toda vez que, en su virtud, añadirá dos acepciones más a la de Covarrubias. De modo que, en definitiva, el Diccionario de

2 Se ha consultado para estas páginas la edición de Martín Riquer. Según la impresión de 1611, con las adiciones de Benito Remigio Noydens, publicadas en la 1674. 
Autoridades no sólo le asignó a contaminar el significado de «manchar, inficionar, macular secretamente y sin que se eche de ver", sino también, en sentido metafórico, el de "corromper, viciar, y depravar alguna cosa, faltando a la verdad o falseándola»; de igual forma que el de "heder, oler mal o despedir de sí mal olor».

De tales formulaciones académicas interesa destacar la irreductible distancia que media entre los dos universos invocados por su conjunto, $y$, por consiguiente, separa a las acepciones de contaminar que componen. Pues si manchar y oler mal apelan a sendas parcelas del mundo perceptible por los sentidos, no lo hacen, sin embargo, el corromper, el viciar ni el depravar que definen la segunda significación de contaminar reseñada, debido al valor metafórico que, al objeto de expresar el falseamiento de la verdad, le imprimía el Diccionario de Autoridades a tales términos. Privándoles, consiguientemente con ello, por esta vez, de los que en rigor les concedía cuando, en virtud de los mismos, designaba acciones con incidencia en el terreno de la realidad tangible. Con lo que, a fin de cuentas, concluía la Academia por comunicarle al significado de contaminar ahora considerado la propiedad de situar la acción que define en el mundo de la moral.

Confirman dicha inferencia las definiciones que el Diccionario concedía a los derivados de contaminar incluidos en sus páginas. A cuyo propósito, no se negará en éstas que tal sea el caso de la correspondiente a contaminado: "participio pasivo del verbo contaminar en sus acepciones". Es obvio que, pues dicha definición apela a las distintas acepciones de contaminar, ratificaba mediante la misma el Diccionario de Autoridades la información que proporcionaba acerca de aquellas. Pero, precisamente por eso, porque no aportaba nada nuevo a lo ya sabido gracias a contaminar, carece la definición de contaminado de interés para el objetivo que aquí se persigue. De ahí que pueda prescindirse de ella y aun de las que, casi en los mismos términos, ofrecen sobre el particular los diccionarios académicos posteriores al de Autoridades, desde 1780 a 1822 , pues ya el de 1833 silencia el vocablo, siguiendo su ejemplo los sucesivos incluido el último.

Más elocuencia emplea el Diccionario de Autoridades al individualizar los significados respectivos de los otros dos derivados más de contaminar de los cuales se ocupa. No en balde, expresa que contaminación equivale a «infección, mácula y corrupción», no sin aclarar que "en el sentido literal tiene poco uso y de ordinario se toma por corruptela, vicio y malignidad en los afectos y pasiones del ánimo, y estragamiento de las costumbres". La información es terminante respecto al poco uso de en la época del sentido literal frente al más extendido por en- 
tonces del figurado. Aunque no parece que el Diccionario de Autoridades quisiera comunicarles ese carácter y conceder valor metafórico a la infección, la mancha y la corrupción, por más que esta última sí aparente mudar en corruptela y concluir el vicio en apenas desorden de las costumbres. En todo caso es clara la nueva invocación académica al orden moral, ante la cual nada tiene de particular que el Diccionario definiera, por último, contaminarse como "corromperse, mancharse, inficionarse con algún vicio, error o culpa».

Catorce años, de 1726 a 1739, tardaría la Academia en ultimar la publicación de los seis tomos que componen el Diccionario de Autoridades, y treinta y uno más en ofrecer la reimpresión corregida y aumentada de su primer tomo, que vio la luz en 1770 . Si bien, contrariamente a lo que dicho proceder permitía pronosticar, la institución no llegó a reeditar ningún tomo más. En su lugar compuso el Diccionario de 1780, con criterios algo distintos de los que empleó para la redacción de su precedente más erudito. Toda vez que al confeccionar el más moderno prescindió la Academia de todas las citas de autoridad y etimologías de las voces, limitándose a definirlas y a dar cuenta de sus correspondencias latinas; para ofrecer a la postre una versión bastante aproximada a la que, con alguna variación en cuanto a información etimológica, terminaría siendo el modelo de diccionario de las últimas ediciones.

En definitiva, con su diccionario de 1780 iniciará la Academia una andadura en la que, de forma ininterrumpida hasta hoy, se ocupará de definir contaminar, bien que no en los mismos términos, de igual modo que algunos derivados suyos, distintos según las ediciones, con la salvedad de contaminación, presente en todas ellas. Así en la de 1780 y posteriores hasta la de 1822, serán contaminación y contaminado; en las comprendidas entre las de 1889 y la de 1956 contaminación y contaminador; y en las de 1970 a 2001 contaminación, contaminador y contaminante.

El que a partir de 1780 prescinda la Academia de contaminarse -recogido, no se olvide, en el Diccionario de Autoridades- y luego de contaminado, para ocuparse más adelante de contaminador y de contaminante después, indican una progresiva pérdida de interés académico por el sujeto paciente de la contaminación, con carácter previo a un aumento paulatino de curiosidad por el sujeto agente de la misma, así como por el elemento o ingrediente concernido por la contaminación. Más allá de tan pobre conclusión no permiten los datos extraer otra, porque nada aportan los sucesivos tratamientos académicos de contaminación, contaminador y contaminante a la información que de suyo proporcionan las definiciones de contaminar a las que acompa- 
ñan. De modo que, como en el caso de contaminado, puede prescindirse de cuanto digan los diccionarios académicos sobre las voces mencionadas. Sólo resulta provechosa su consulta cuando de contaminar se trata.

Pues bien, casi las mismas cinco acepciones del término, con muy ligeras variantes, ofrecerán las ediciones académicas del diccionario comprendidas entre 1780 y 1956. Las cuales, siguiendo el precedente sentado por el de Autoridades, apelaban tanto al mundo de la realidad tangible como al figurado. En efecto, a la realidad perceptible por los sentidos se refieren esos diccionarios cuando expresan que el vocablo significa "penetrar la inmundicia algún cuerpo, causando en él manchas y mal olor", o afirman que contaminar equivale a "contagiar, inficionar». Mientras que lo metafórico es patente cuando definen el término como "corromper, viciar o alterar algún texto u original»3; le asignan el significado de "pervertir, corromper, mancillar la pureza de la fe o de las buenas costumbres» ${ }^{4}$; o dicen: "hablando de la Ley de Dios, lo mismo que profanarla».

Alguna evolución se aprecia entre el primer tratamiento académico de contaminar y estos otros posteriores recién mencionados. En su virtud se juzga aquí más nítidamente deslindables las dos esferas que, desde el Diccionario de Autoridades, vienen estimándose aludidas por el término. Téngase presente que en lo tocante a su vertiente material, las ediciones más modernas del diccionario ahora consideradas prescinden de lo superfluo, que el contaminar ya no tiene que ser "secretamente y sin que se eche de ver», ni guarda relación alguna con el propósito de reservar u ocultar. Lo importante son ahora la penetración de la inmundicia en un cuerpo y sus consecuencias para éste, manifestadas en forma de mancha y mal olor.

\subsection{De sus acepciones más modernas}

Bastante distinto del tratamiento académico hasta aquí descrito de contaminar es el que le dispensó el Diccionario de 1970 y reprodujeron sus ediciones posteriores, incluida la de 1989, como consecuencia del cual concluiría obteniendo aquél una fisonomía desconocida hasta entonces, menos apegada a lo figurado que a lo tangible. Pues, en efecto,

3 Desde la edición de 1884 conocerá dicha acepción un ligero cambio inherente a la sustitución de "algún texto" por "un texto".

4 Desde la edición de 1925 el diccionario dirá sólo "costumbres" y no "buenas costumbres". 
se apartan tales diccionarios de sus precedentes temporalmente más próximos en dos oportunidades, trascendentales, de modo inmediato, para la vertiente o dimensión material de contaminar que, desde el primer momento, le reconoció la Academia.

Téngase en cuenta al respecto que la principal medida revisora de sus formulaciones previas a 1970 consistió en incorporar a su Diccionario de esa fecha una acepción completamente inédita, en cuya virtud contaminar significaba tanto como "alterar la pureza de alguna cosa, como los alimentos, el agua, el aire, etc". Acerca de la cual conviene tener presente, para valorar en sus justos términos el alcance de tan incuestionable apelación al mundo de la realidad tangible, que la Academia la convirtió además en la primera acepción de contaminar, ha de suponerse que haciéndose eco de un radical cambio de percepción entre hispanohablantes acerca de lo que la palabra designaba.

La relevancia de dicha medida casi eclipsa la menor entidad de la segunda acción, igualmente revisora de sus planteamientos, practicada por la Academia en su Diccionario de 1970. Se inscribe ésta en un contexto definido por la decisión que adoptó la institución de mantener las acepciones, con sus correspondientes significados, de contaminar que ofrecía el Diccionario de 1956, con la única salvedad de la que allí ocupaba el tercer lugar, en donde, como se recordará, recibía el término el significado de "corromper, viciar o alterar algún texto u original». Pues en el Diccionario de 1970 se preocupó la Academia de asignarle a la cuarta acepción de contaminar ${ }^{5}$, éste otro más técnico y preciso: "alterar la forma de un vocablo o texto por la influencia de otro".

He aquí la segunda variación que muestra el Diccionario de 1970 con respecto a su precedente. De menor entidad que la primera, desde luego, pero tan expresiva como ella de un cambio de actitud en la Academia. Todavía más evidente si ambas variantes se contemplan en conjunto. Pues entonces no cabe ninguna duda respecto a que por vez primera la institución enfatizaba la vertiente de contaminar referida a la realidad tangible. Harto significativo, en este sentido, es que el Diccionario de 1989, idéntico al de 1970, según se ha dicho, en su tratamiento de contaminar, incluya una representación gráfica de un río con algunos objetos flotando en él, acompañada del siguiente pie: "contaminación del río Tajo».

5 No se olvide que dicho Diccionario incorporaba una acepción nueva del vocablo y mantenía, en los términos expresados, las que incluía el Diccionario de 1956, desplazando de lugar, como consecuencia, a estas últimas. 
La misma tendencia muestran los diccionarios de 1992 y de 2001, coincidentes además tanto en restringir otra vez a cinco las acepciones de contaminar, a costa de omitir la que, de esa voz, ofrecían los diccionarios editados entre 1970 y 1989 en segundo lugar —o en el primero si se habla de los publicados entre 1780 y $1956{ }^{6}$; como en reproducir prácticamente las demás acepciones ${ }^{7}$. Con eso concluyen las afinidades entre ambos diccionarios y, por consiguiente, también el modo en que guardan fidelidad a la referida preferencia del Diccionario de 1970 por lo tangible. Pues, no en balde, modificaron sucesivamente aquellos diccionarios el tenor literal de la primera acepción que el Diccionario de 1970 expresaba de contaminar, sin alterar por eso ninguno sustancialmente su sentido.

Desde luego que lo convalida el Diccionario de 1992, cuya primera acepción de contaminar se asienta sobre la base de la que también en este lugar ofrecía el Diccionario de 1970. Según lo evidencia el enunciado de la más moderna, algo más completo que el de su fuente inspiradora: "Alterar, dañar alguna sustancia o sus efectos la pureza o el estado de alguna cosa. CONTAMINAR los alimentos, el agua, el aire, los organismos. U.t.c.prnl. SE HA CONTAMINADO de radioactividad». Más concisa, sin que eso le reste ni un ápice de elocuencia, es la definición de contaminar que recibe en el Diccionario de 2001 su primera acepción, sea como fuere fundada, de igual modo que la expuesta del Diccionario de 1992, en aquel enunciado que el Diccionario de 1970 le dedicara a la primera acepción del término. Júzguese si no a la vista del modo en que el Diccionario de 2001 se manifiesta al respecto: "Alterar nocivamente la pureza o las condiciones normales de una cosa o un medio por agentes químicos o físicos".

Sin lugar a dudas que este último dato es en sí mismo destacado, aunque conviene completarlo con los que aportan las restantes acepciones de contaminar registradas en el Diccionario de 2001 porque todas juntas proporcionan información semántica ineludible para abordar la interpretación gramatical de las normas que al usar el vocablo vengan comunicadas por él. Pero considérense, además de cuanto sobre el mismo dice ese Diccionario, las noticias adicionales que se han obte-

6 «Penetrar la inmundicia algún cuerpo causando en él manchas y mal olor».

7 Sólo una pequeña diferencia, producto de un prurito por la concisión, separa a los enunciados que los Diccionarios de 1992 y 2001 encierran de la última acepción de contaminar. Pues el de 1992 afirma: "Dicho de la Ley de Dios profanarla, quebrantarla». Mientras que el de 2001 dice: "Profanar o quebrantar la Ley de Dios». Sin que, en ningún caso, como puede comprobarse resultara afectado el sentido que mucho antes de 1970 le asignara la Academia. 
nido en torno a la evolución del tratamiento académico de contaminar y obsérvese cómo entonces se enriquece la información que presta el Diccionario de 2001 al respecto. Desde luego que la de orden semántico, pero también la ligada a ella, que ha de presumirse ofrecen siempre los diccionarios académicos, relativa a los significados que en cada momento atribuyen los hispanohablantes a las palabras. En resumidas cuentas, se entiende aquí que, mediante los datos acopiados en torno a los significados de contaminar, puede obtenerse una interpretación gramatical impregnada de sociología de las normas enunciadas mediante ese término que, en cuanto tal, incorpore la realidad del tiempo en que han de aplicarse.

\section{HIPÓTESIS ACRÓNICA SOBRE LOS POSIBLES USOS NORMATIVOS DE CONTAMINAR}

No se negará que a la norma le sea dado versar sobre cualquier acepción de contaminar consignada en los diccionarios académicos consultados o, mejor, que pueda adoptar como objeto los ámbitos de realidad invocados por cada una de esas acepciones, con el efecto consiguiente de importarle al Derecho la consiguiente regulación. Es más, a este propósito no faltan supuestos expresivos de la atención normativa que, desde hace años, reciben en España asuntos tales como la calidad del aire, la salud colectiva, la propiedad intelectual o la libertad de conciencia y los sentimientos religiosos.

En cuanto a la calidad del aire o, por decirlo con una paráfrasis de la primera acepción de contaminar que ofrece el Diccionario de la Real Academia, la conservación de su pureza o condiciones normales frente al riesgo de su alteración por agentes químicos, interesa subrayar ciertas formulaciones de la Ley 38/1972, concretamente de su Exposición de Motivos, por el rigor con en ellas se ciñe el legislador a lo enunciado en la primera acepción de contaminar que ofrecía el Diccionario de 1970. Dígase si no a la vista de cómo se expresaba aquél a la hora de definir los objetivos perseguidos por la Ley:

"El aire es un elemento indispensable para la vida, y su utilización debe contribuir a preservar su pureza dentro de unos límites que no perturben el normal desarrollo de los seres vivos sobre la tierra, ni atenten contra el patrimonio natural y artístico de la Humanidad ${ }^{8}$.

8 Exposición de Motivos de la Ley 38/1972, de 22 de diciembre, de protección del ambiente atmosférico. El subrayado es nuestro. 
Desbordaría con mucho el objetivo que se persigue en estas páginas informar con el detenimiento debido de las numerosas normas que, desde hace años, le han indicado a las autoridades sanitarias de nuestro país, el procedimiento a seguir a fin de prevenir o afrontar situaciones de emergencia para la salud pública o, por expresarlo con los términos que emplea la Ley Orgánica 3/1986, de 14 de abril, en su artículo primero, de urgencia o necesidad para la misma. De ahí que, a los efectos de evidenciar el interés del legislador por el sector de la realidad invocado en la segunda acepción del Diccionario de la Real Academia, se juzgue aquí suficiente con la cita de la ley expresada y de la Ley 14/1986, de 25 de abril, de medidas especiales en materia de sanidad pública, como ejemplos de normaciones atentas al tratamiento, entre posibles enfermedades, de las contagiosas.

En torno a uno de los elementos integrantes del universo reseñado en la tercera acepción de contaminar que encierra el Diccionario de la Real Academia versa el Código Penal cuando, a propósito de la propiedad intelectual, tipifica como delito, su artículo 270, la transformación de una obra literaria, artística o científica. Como, a su vez, atañe a lo consignado sobre contaminar en la cuarta y quinta acepciones del Diccionario el artículo 525 del Código Penal, considerando que, en su virtud, es punible la conducta de quienes «para ofender los sentimientos de los miembros de una confesión religiosa, hagan públicamente, de palabra, por escrito o mediante cualquier tipo de documento, escarnio de sus dogmas, creencias, ritos o ceremonias, o vejen, también públicamente a quienes los profesan o practican».

\section{INFERENCIA SINCRÓNICA RESPECTO AL SENTIDO QUE ADQUIERE CONTAMINAR EN EL TRATADO POR EL QUE SE ESTABLECE UNA CONSTITUCIÓN PARA EUROPA}

Sin embargo, no parece que el Tratado por el que se establece una Constitución para Europa se interese por cuantos asuntos salen a relucir en las definiciones que los diccionario académicos asignan a las diferentes acepciones de contaminar que respectivamente contemplan, como así cabe deducir de una mera aproximación al contexto en que se inscribe el empleo del término por dicho Tratado, no obstante la ausencia de toda información por su parte respecto al sentido que le atribuye a contaminar en las dos ocasiones que usa el término.

La primera en el Art. III-233.2, en donde comenzará el precepto por completar la lista de los objetivos que, según el Art. III-233.1, se propone perseguir la Unión Europea en lo medioambiental con la formu- 
lación de otro más, el de alcanzar «un nivel de elevado protección, teniendo presente la diversidad de situaciones existentes en las distintas regiones de la Unión». A reglón seguido de lo cual enumerará la disposición ahora analizada los principios sustentadores de dicho política, mencionando entre ellos el de "quien contamina paga". La segunda vez que el Tratado se sirve de contaminar es en el Art. III-234.5, para precisar, respecto al principio de quien contamina paga, que, cuando una acción emprendida para la realización de los objetivos definidos en el Art. III-233.1, implique costes desproporcionados para un Estado miembro, dicha acción irá acompañada, bien de excepciones de carácter temporal, bien de apoyo financiero con cargo al Fondo de Cohesión, si no de ambas medidas.

Tales son las disposiciones del Tratado que emplean expresamente el verbo contaminar, aunque, como se adelantaba, ninguna de las dos ofrezca indicio alguno sobre el sentido en que usan el término, ni permitan aproximarse a éste por la vía indirecta de identificar el sector de la realidad al que uno y otro precepto apelan con la expresión medio ambiente. A pesar de encuadrarse ambos en el marco del tratamiento dispensado por el Tratado a lo medioambiental, pues tampoco aclaran nada ninguno de ellos a su respecto.

Eso no quiere decir que haya de renunciarse a todo intento de aproximación al sentido más verosímil que contaminar tiene o puede tener en el Tratado por el que se establece una Constitución para Europa. A cuyo propósito se seguirá el procedimiento de indagar, también en términos sólo aproximativos, sobre el sector de realidad concernido por la expresión medio ambiente, acudiendo a otros preceptos distintos de los mencionados, cualquiera que sea el lugar del Tratado en que se ubiquen. Por razones de índole exclusivamente sistemática interesa iniciar las pesquisas oportunas analizando los preceptos más próximos, por su localización, a los mencionados arts. 233.2 y 234.5. De modo que se acudirá a su Parte Tercera - rotulada, "de las políticas y el funcionamiento de la Unión»-, concretamente a su Título III —epigrafiado "políticas y acciones internas»-, para consultar de su Capítulo III -rubricado, "políticas en otros ámbitos»-, su Sección Quinta —titulada, "medio ambiente»-; ocasión habrá de buscar información complementaria en las demás partes del Tratado. Las cuales muy bien pueden representarse gráficamente como círculos concéntricos trazados alrededor de los expresados preceptos. De modo que se empleará dicha metáfora de la figura geométrica propuesta para exponer el plan metodológico de acuerdo con el que pretende abordarse la búsqueda de información adicional. Pues, en definitiva, se tiene el propósito de recorrer las diferentes divisiones de la pretendida Constitución Europea 
en orden inverso al que se han enumerado, esto es, del círculo más próximo al más alejado de ese centro, y así sucesivamente hasta consultar la Parte III del Tratado, para hacer luego otro tanto con sus dos primeras partes.

Con arreglo al plan metodológico expresado se impone comenzar examinando los preceptos más próximos o cercanos a los aquí erigidos en en centro geométrico de la representación propuesta. Análisis este que arroja un resultado ciertamente provechoso, pues el Tratado por el que se establece una Constitución para Europa encierra en el lugar indicado, esto es, en su Parte III, concretamente en su Título III, y todavía más en la Sección Quinta de su Capítulo III, información suficiente para deducir de la misma conclusiones tan satisfactorias acerca del asunto que interesa ahora dilucidar como para obviar la consulta de otros apartados del Tratado. Los cuales, no conviene pasar por alto, sin embargo, siquiera sea porque confirman esas inferencias.

La primera de ellas es el carácter marcadamente económico que el Tratado confiere a las políticas medioambientales asumibles, en su virtud, por la Unión?. Harto elocuente al respecto son las disposiciones de aquél que imponen a ésta, a la hora de elaborar dichas políticas, tener en cuenta su propio grado de desarrollo económico, así como el desarrollo equilibrado de sus regiones (Art. III-233.3.d); autorizan al Consejo de Ministros para que adopte, por unanimidad, medidas de carácter fiscal en este terreno (Art. III-234.2.a); o imponen a los Estados miembros la obligación de financiar y ejecutar la política de la Unión en materia de medio ambiente (Art. III-234.4). Sin que falten preceptos, ubicados en otros lugares del Tratado, que muevan a considerar igualmente impregnado de influencia económica el tratamiento éste le dedica al medio ambiente. Tal es el caso de la previsión relativa a crear un Fondo de Cohesión para financiar, entre otros, proyectos medioambientales (párrafo segundo del Art. III-223); así como de las diversas alusiones que efectúa el Tratado al equilibrio entre medio ambiente y desarrollo sostenible en el Art. III-292.2. f), el Art. III-119, y el Art. II-97.

La segunda de las inferencias más arriba anunciada es la extraible de la relación que en su Art. III-234.2.b) establece el Tratado entre el me-

9 Si bien no es ajeno el Tratado a la existencia de un medio ambiente no económico, del que se ocupa en el párrafo segundo del Art. III-233.2. Según el cual: «En este contexto, las medidas de armonización que respondan a exigencias de la protección del medio ambiente incluirán, en los casos apropiados, una cláusula de salvaguardia que autorice a los Estados miembros a adoptar, por motivos medioambientales no económicos, disposiciones provisionales sometidas a un procedimiento de control de la Unión». 
dio ambiente y otros sectores de la realidad tradicionalmente objeto de atención normativa en los ordenamientos nacionales de los Estados miembros. Pues lo allí enunciado consiente sostener que no le es indiferente a lo medioambiental ninguna medida adoptada por la Unión o por los Estados miembros en cualquiera de esas otras materias. No en balde, dispone el mencionado precepto que, sin perjuicio de las acciones a emprender para la realización de los objetivos asumidos por la Unión en materia de medio ambiente, puede el Consejo de Ministros, por unanimidad, adoptar leyes o leyes marco europeas en los ámbitos de la ordenación territorial, la gestión de los recursos hídricos, la utilización del suelo y la gestión de los residuos. Enumeración esta que amplía el Art. III-234.2.c) del Tratado a la energía, o, más exactamente a la elección por un Estado miembro entre diferentes fuentes de energía o a la estructura general de su abastecimiento energético, como así lo confirma, por su parte, el Art. III-256.1, según el cual la política de la Unión en el ámbito de la energía tendrá en cuenta la exigencia de conservar y mejorar el medio ambiente.

Pues bien, si las disposiciones consultadas expresan cautela porque una acción ejercitable sobre cualquier ámbito material consignado en ellas pueda afectar a lo medioambiental, no es descabellado estimar que dicho planteamiento se asienta sobre la base de considerar a tales materias, en primer lugar, perfectamente diferenciables de la designada con la expresión medio ambiente; al tiempo que, en segundo término, bien afines o colindantes con esta última —es decir, tan próximas a la misma que puedan llegar a solapar algún sector de la realidad a que apela-, bien susceptibles de convertirse en objeto de medidas inconciliables con los fines que, según el Art. III-233.1 y 2, pretende alcanzar la Unión en medio ambiente. De otro modo, no se entiende que decisiones adoptadas en ámbitos estimables ajenos a lo medioambiental, puedan interferir e incluso comprometer el éxito de su política en ese terreno.

En resumidas cuentas, el Tratado por el que se establece una Constitución para Europa contempla al medio ambiente como una materia impregnada de naturaleza económica, que, además, colinda o guarda una estrecha relación con las atinentes a la ordenación territorial, la gestión de los recursos hídricos, "el uso del suelo, con excepción de la gestión de los residuos", y la energía, pues no es indiferente para lo medioambiental qué fuente de energía o estructura energética adopten los Estados miembros de la Unión. Conviene subrayarlo, toda vez que, a la vista de tales deducciones, cabe concluir afirmando que no todas las acepciones de contaminar, enunciadas en el Diccionario de la Real Academia son de utilidad a la hora de aproximarse al sentido con 
que lo usa el Tratado por el que se establece una Constitución para Europa.

De modo que, para interpretar sus determinaciones, muy bien pueden obviarse las acepciones figuradas de contaminar, las que hablan de perversión o corrupción de la fe o las costumbres, y de profanar o quebrantar la Ley de Dios. Como también cabe prescindir de las menos o nada figuradas que le asignan al término el significado de alterar la forma de un vocablo o texto por la influencia de otro, o el de contagiar o inficionar. En este último caso, no porque se infiera de cuanto acaba de decirse, sino porque así autoriza a sostenerlo el que, según el Art. I14.2 del Tratado, sean objeto de competencia compartida, entre la Unión y los Estados miembros, "los asuntos comunes de seguridad en materia de seguridad pública», atribuyéndole así a ésta la consideración de ámbito material autónomo con el cual vendría a relacionarse inmediatamente la infección o el contagio académicos.

En cambio, adviértase como la armonía es completa entre la primera acepción de contaminar registrada en el Diccionario de la Real Academia y lo que acerca del medio ambiente ha podido inferirse hasta ahora de las disposiciones a él referidas del Tratado por el que se establece una Constitución para Europa. Nótese que es perfectamente conciliable esa idea de medio ambiente, todavía difusa, alcanzada por vía deductiva, con la definición correspondiente al primera acepción de contaminar que ofrece el Diccionario. Según la cual, no se olvide, que contaminar significa tanto como "alterar nocivamente la pureza o las condiciones normales de una cosa o un medio por agentes químicos o físicos".

\section{DEL VÍNCULO ANUDABLE ENTRE CONTAMINACIÓN Y MEDIO AMBIENTE A TENOR DE LO DISPUESTO EN EL TRATADO POR EL QUE SE ESTABLECE UNA CONSTITUCIÓN PARA EUROPA}

Sin embargo, si lo enunciado en el Tratado por el que se establece una Constitución para Europa alienta a establecer un vínculo entre contaminar y medio ambiente, no es sólo porque una aproximación al tratamiento que allí recibe este último permite elegir entre los varios significados lingüísticos de contaminar aquél que con más posibilidades cuenta de ser el empleado por el Tratado, porque apele dicho significado al sector de realidad que más verosímilmente se erige en el objeto de sus proposiciones normativas sobre lo medioambiental. También se estima anudable dicho vínculo porque la conclusión que así se alcance consiente utilizarse para desentrañar el significado que la ex- 
presión medio ambiente adquiere en el Tratado. De modo que, en definitiva, se juzgan comunicados en dicho documento medio ambiente $y$ contaminar por una relación de naturaleza transitiva y recíproca.

Desde luego que gracias a la primera acepción de contaminar que ofrece el Diccionario de la Real Academia, adquieren plenitud de sentido el párrafo segundo del Art. II-233.2 y el Art. III-234.5 del Tratado por el que se establece una Constitución para Europa, esto es, las disposiciones del mismo que se sirven del término para enunciar el principio de "quien contamina paga». Obsérvese cómo, en efecto, es racional, por comprensible, la proposición normativa que exige pagar a quien altera nocivamente la pureza o las condiciones normales de una cosa o medio por agentes químicos o físicos. Pero si interesaba resaltarse dicho asunto, con tanto mayor motivo procede obrar de igual modo con otro concatenado a él, y es que, como acaba de decirse, se estima aquí que esa acepción de contaminar le confiere a la expresión medio ambiente del Tratado un significado congruente, de acuerdo con el cual es posible su conceptuación, bien que todavía no en términos jurídicos.

Acúdase a los preceptos del Tratado que mencionan de modo expreso el medio ambiente. Dígase si el objetivo que, en virtud de lo dispuesto en el Art. 1-3.3 de la pretendida Constitución Europea, asumiría la Unión de cuidar porque su proceder prospere «en un nivel elevado de protección y mejora de la calidad del medio ambiente ${ }^{10}$, no admite entenderse como una declaración de principio hostil a la contaminación y favorable a proteger, por tanto, la esencia y cualidades de una cosa frente a cualquier acción, con efectos nocivos para la misma, dimanante de agentes físicos o químicos.

De estimarse practicable, como aquí se hace, esa inteligencia de lo enunciado en la citada disposición, es incuestionable entonces que el antagonismo entre los dos términos del binomio en cuestión, la naturaleza de una cosa y su vulnerabilidad frente a la influencia de agentes físicos o químicos, es lo nuclear del significado que cabe atribuir y se le asigna en estas páginas al concepto de medio ambiente que utiliza el Tratado. Lo de menos es la cosa o el agente contaminante aisladamente considerados. Vistos desde esta perspectiva carecen una y otro para el medio ambiente del interés que inmediatamente adquieren puestos en relación. Cuestión distinta es que, como el universo todo está en interacción y debido a ello todo muda de naturaleza, el ser humano decida que algunas cosas no cambien, naturalmente que allí

10 También el Art. II-97 habla de "un nivel elevado de protección del medio ambiente y la mejora de su calidad». 
hasta donde se lo permiten los medios y las fuerzas con que cuenta para impedirlo, y con arreglo a una escala de valores que se comprende presida su instinto de supervivencia, en relación con el cual la salud es el mejor testigo de sus expectativas de vida.

No se negará que esa decisión acerca de lo protegible carezca de consecuencias para la identidad del medio ambiente, pero porque es casi seguro que esa selección apelará, de un modo u otro, a lo perjudicial para lo incluido en la misma, manifestándose entonces en interacción las cosas y sus agentes contaminantes inmediatos. Pues, según ha quedado dicho, se juzga insatisfactorio el intento de identificar el medio ambiente con ese repertorio de cosas destinadas a protegerse. Al fin y al cabo se defiende en estas páginas la tesis, inspirada en las formulaciones del Tratado relativas al medio ambiente, en cuya virtud su concepto descansa en el de contaminar, por la relación que cabe establecer entre una cosa y los agentes contaminantes que pueden perjudicar o dañar su naturaleza.

El concepto resultante se entiende además conciliable con las disposiciones del Tratado que, de modo explícito, se ocupan del medio ambiente. Pues, pasando por alto el tratamiento que allí recibe la dimensión económica del medio ambiente, carente de interés, en relación con el asunto que ahora importa, sintonizan con dicha noción de lo medioambiental no ya los sucesivos Ilamamientos del Tratado a la necesidad de conjugar ese objetivo de proteger el medio ambiente con el fomento del desarrollo sostenible ${ }^{11}$; o la atención que presta el Tratado a los avances científicos, todo parece indicar que por considerarlos instrumentalizables para alcanzar ese fin proteccionista del medio ambiente, en relación con el cual tanto protagonismo adquiere la lucha contra la contaminación ${ }^{12}$; sino también el al definir los objetivos que se propone alcanzar la Unión con su política medioambiental hable el Tratado de conservar, proteger y mejorar la calidad del medio ambiente, de proteger la salud de las personas, de utilizar prudente y racionalmente los recursos naturales, de fomentar medidas a escala internacional destinadas a hacer frente a problemas regionales o mundiales del medio ambiente, y de alcanzar un nivel de protección elevado, teniendo presente la diversidad de situaciones existentes en las distintas regiones de la Unión ${ }^{13}$; o que asuma como principios rectores de su actuación en este campo la cautela y la acción preventiva, la corrección de

11 Cfr. Art. II-97, Art. III-119 y Art. III-233.3.d).

12 Cfr. Art. III-172.3, Art. III-172.5 y Art. III-233.3.a).

13 Cfr. Art. III-233.1 y Art. III-233.2. 
los atentados al medio ambiente en la fuente misma, preferentemente, y el ya conocido de quien contamina paga.

De igual modo, encuentra acogida en el concepto de medio ambiente que aquí se ha propuesto el tipo de variables que, de acuerdo con el Tratado por el que se establece una Constitución para Europa, habrá de tener en cuenta la Unión al elaborar su política medioambiental, considerando que aquellas han de ser, entre otras, los datos científicos y técnicos disponibles, y las condiciones del medio ambiente en las diversas regiones de la Unión. Como asimismo pueden contemplarse en armonía con ese concepto de medio ambiente las medidas extraordinarias que, según el Tratado, le es dado adoptar, por unanimidad, al Consejo de Ministros en los ámbitos de la ordenación territorial, la gestión cuantitativa de los recursos hídricos que afecten directamente o indirectamente a la disponibilidad de dichos recursos, la utilización del suelo - salvo en lo relativo a la gestión de los residuos, y las que afecten de forma significativa a la elección por un Estado miembro entre diferentes fuentes de energía y la estructura general de su abastecimiento energético ${ }^{14}$. $Y$ otro tanto cabe sostener, por último, del propósito que, en el terreno de la acción exterior de la Unión, enuncia el Tratado cuando habla de contribuir a elaborar medidas internacionales tendentes a la protección y mejora de la calidad del medio ambiente, así como a la gestión de los recursos naturales mundiales, afin de garantizar el desarrollo sostenible ${ }^{15}$.

\subsection{El tratamiento de la contaminación por el Derecho Comunitario derivado}

Falta por saber si cuanto hasta aquí se ha dicho del tratamiento que recibe el medio ambiente en el Tratado por le que se establece una Constitución para Europa puede reproducirse observando este asunto con arreglo a criterios de orden normativo y jurisprudencial, en virtud de los cuales se obtenga una visión del mismo que, precisamente por eso, admita el calificativo de jurídica. Desde luego que sobre este particular tienen la última palabra los órganos de la Unión facultados para el desarrollo de lo dispuesto en el Tratado, así como su Tribunal de Justicia. Aunque la natural ausencia de dicho desarrollo normativo y, por consiguiente, de jurisprudencia a él referida, no es, sin embargo, nin-

${ }^{14}$ Cfr. Art. III-234.2.c), así como el Art. III-256.1 que declara la necesidad de cohonestar las políticas de la Unión relativas al medio ambiente y la energía.

15 Cfr. Art. III-292.2.f). 
gún obstáculo para proceder al análisis de contaminar y medio ambiente desde la óptica propuesta, esto es, de acuerdo con los parámetros referidos. Pues resulta incuestionable que, lejos de actuar en el vacío, los redactores del Tratado por el que se establece una Constitución para Europa contaban para ejecutar su tarea con la ayuda del Derecho Comunitario Europeo. Al cual, como cabía esperar que sucediera, han vinculado aquellos dicho Tratado, no en balde inspirado en las normas integrantes de ese ordenamiento jurídico, enriquecidas con la jurisprudencia generada por el Tribunal de Justicia de las Comunidades Europeas con motivo de su aplicación ${ }^{16}$. Pues, en efecto, tal es la procedencia de las categorías que usa el Tratado, incluidas, claro está, las de contaminar y las de medio ambiente, a las cuales, no se olvide, se le dedican estas consideraciones de ahora con la intención de argumentar que, como se adelantaba, vistas desde la perspectiva jurídica descrita, también contaminar o, más exactamente, el vínculo anudable entre una cosa y sus contaminantes, define al medio ambiente.

Casi es ocioso añadir que la ejecución de dicho Tratado exige conocer previamente, como es debido, qué dice el Derecho Comunitario Europeo sobre contaminar y medio ambiente, pues resulta obvio que sólo gracias a esa información podrá dilucidarse si en dicho ordenamiento ambas categorías están relacionadas, y, de advertirse que así es y revelarse, además, tal relación particularmente intensa, emitir un juicio respecto a si cabe entender que una se erige en fundamento conceptual de la otra.

De acuerdo con dicho planteamiento interesa comenzar subrayando la abundante información que acerca de contaminar o, más exactamente, sobre sus efectos, ofrece el Derecho Comunitario Europeo, en

${ }^{16}$ Congruentemente con el espíritu que anima al Tratado de asentarse sobre esa realidad jurídica previa del Derecho Comunitario Europeo vigente, según autorizan a sostenerlo las manifestaciones de su Exposición de Motivos que expresan claramente la voluntad de convalidarlo. Pues, en efecto, así entendidas adquieren plenitud de sentido las declaraciones allí efectuadas con el propósito de mejorar el reparto competencial entre la Unión y los Estados miembros; de fusionar los tratados y de atribuir a la Unión personalidad jurídica; de simplificar sus instrumentos de actuación, así como el procedimiento decisorio, haciendo más transparente y comprensible el funcionamiento de las instituciones europeas; de mejorar la estructura y reforzar el papel de cada una de las tres instituciones de la Unión, teniendo en cuenta, particularmente, las consecuencias de la ampliación. De igual modo que, sin duda, expresa esa misma intención la redacción de un Proyecto de Tratado por el que se instituya una Constitución para Europa como respuesta a la cuestión suscitada en la Declaración Laeken de si la simplificación y la reorganización de los Tratados no deberían preparar el terreno para la adopción de un texto constitucional. 
donde pueden encontrarse hasta dos definiciones de contaminación, según que la acción contaminante se aprecie, de modo inmediato, en el agua o, mejor, en las aguas, o en la atmósfera. Consúltense si no, respectivamente, la Directiva 76/464/CEE del Consejo, de 4 de mayo de 1976, relativa a la contaminación causada por determinadas sustancias peligrosas vertidas en el medio acuático de la Comunidad, y la Directiva 84/360/CEE del Consejo, de 28 de junio de 1984, relativa a la lucha contra la contaminación atmosférica procedente de las instalaciones industriales.

Pues, efecto, la Directiva 76/464/CEE define, en su Art. 1.2.e), la contaminación como "el vertido ${ }^{17}$ de sustancias o de energía efectuado por el hombre en el medio acuático, directa o indirectamente, que tenga consecuencias que puedan poner en peligro la salud humana, perjudicar los recursos vivos y el sistema ecológico acuático, causar daños a los lugares de recreo u ocasionar molestias para otras utilizaciones legítimas de las aguas».

De la definición se desprende con claridad el esfuerzo por la catalogación exhaustiva de los agentes contaminantes que realiza el legislador comunitario, con éxito, ha de añadirse, pues sin duda que logra convertir a todos, abstracción hecha de cual sea su naturaleza, física o química, cuando para identificarlos habla de "sustancias o de energía». Igualmente nítida es la formulación que dedica la Directiva 76/464/CEE a los sujetos agente y paciente de la contaminación, pues su enunciado no deja lugar a dudas sobre su respectiva identidad que, en el primer caso, corresponde al hombre cuya acción resulte de modo directo o indirecto contaminante, es decir, que también las conductas humanas no recognoscibles como tales sino en potencia, pero que a la postre concluyen contaminando, por descuido o negligencia, convierten a quien las sigue en contaminador.

Tampoco hay ninguna duda sobre el sujeto paciente de la contaminación registrado en la definición de tal que viene comentándose. Ésta, reserva esa consideración al medio acuático. No se pase por alto, sin embargo, que la norma condiciona su tutela a que la alteración negati-

17 La Directiva también se ocupa de aclarar, en su Art. 1.2.d), que vertido significa "la introducción en las aguas previstas en el apartado 1 (esto es, las aguas interiores superficiales, las aguas marítimas territoriales, las aguas interiores del litoral y las aguas subterráneas) de las sustancias enumeradas en la lista I y en la lista II del Anexo, con excepción de los vertidos de lodos de dragado", "vertidos operativos efectuados desde buques en las aguas de mar territoriales" y "la inmersión de residuos efectuada desde buques en las aguas territoriales". Los cuales, no son objeto de regulación por la Directiva porque tienen su propia regulación. 
va de las aguas ocasione alguna de las consecuencias que anuda a esa contaminación, porque de la misma resulte peligro, perjuicio, daño o molestia, según el caso, para los bienes que expresamente menciona. De donde se sigue que al legislador europeo no le interesa otra contaminación del agua que la susceptible de producir los efectos que especifica para salud humana, los recursos vivos y el sistema ecológico acuático, los lugares de recreo y otras utilizaciones legítimas de las aguas. Lo que convierte a esos bienes tutelados por la norma en decisivos a la hora de determinar si existe o no la contaminación porque se aprecie en ellos los efectos de la misma señalados.

Pero aunque así sea y aun cuando en la selección de esos bienes jurídicamente protegidos hayan podido influir las ciencias naturales, porque desde su óptica no se conciba que pueda contaminarse el medio acuático sin manifestarse alguno de los efectos enumerados por la norma, conviene no olvidar que se trata de una construcción jurídica de suyo revisable en cuanto a los bienes jurídicos merecedores de tutela, sin merma alguna, por eso, para lo esencial de la contaminación que, según se entiende aquí, seguirá siendo la alteración nociva de la pureza o las condiciones normales del medio acuático por agentes físicos o químicos, cualesquiera que sean los testigos o indicadores elegidos por el legislador para verificar este hecho.

Por su parte, dispone el Art. 2.1 de la Directiva 84/360/CEE que ha de entenderse por contaminación atmosférica "la introducción en la atmósfera, por el hombre, directa o indirectamente, de sustancias o de energía que tengan una acción nociva de tal naturaleza que ponga en peligro la salud del hombre, que cause daños a los recursos biológicos y a los ecosistemas, que deteriore los bienes materiales y que dañe o perjudique las actividades recreativas y otras utilizaciones legítimas del medio ambiente».

Obsérvese la enorme influencia de la formulación correspondiente a la Directiva 76/464/CEE, reproducida más arriba, en la recién transcrita de la Directiva 84/360/CEE. ¿Cómo negar que esta define la contaminación casi en los mismos término que lo hacía aquella?. Sin embargo, siendo evidente el gran parecido entre ambas definiciones, no son idénticas. Difícilmente podrían serlo teniendo en cuenta, de una parte, que el medio acuático, sujeto paciente de la contaminación en la Directiva 76/464/CEE, le cede el puesto a la atmósfera en la Directiva $84 / 360 / C E E$, y considerando, de otra, que a esa diferencia fundamental vienen a sumársele algunas más. Estas últimas, de menor cuantía si se quiere, en comparación con aquella, pero que son de enorme interés para cuestión ahora por dilucidar y que, en consecuencia, no se pasa- 
rán por alto, muy bien puede haberlas propiciado ese cambio relativo al sujeto paciente de la contaminación, y acaso se expliquen satisfactoriamente en razón del tiempo transcurrido entre la aprobación de una y otra Directiva, desde el momento en que admiten entenderse las diferencias entre ambas a que ahora se hace referencia como una sencilla mudanza, de índole diacrónica, en la percepción de la contaminación.

Tales divergencias en los correspondientes tratamientos de ese fenómeno por las Directivas 76/464/CEE y 84/360/CEE, conciernen no tanto a los bienes jurídicos que la primera de esas normas quiere amparar frente a la contaminación, cuanto al grado de salvaguarda que ésta les proporciona, además de a otro allí silenciado que exclusivamente menciona la segunda., Téngase en cuenta que si bien hace suyo la más moderna el catálogo completo de materias tuteladas por su precursora, no les dispensa a todos la misma protección que aquella, y que, además, amplía la Directiva 84/360/CEE esa lista que convalida. Pues, en efecto, dicha reválida no siempre alcanza a los diferentes niveles de nocividad considerados en la Directiva 76/464/CEE soportables, respectivamente, por los bienes que intenta preservar. De modo que, dicho sea en otros términos, se aparta la Directiva 84/360/CEE de su predecesora al definir el criterio certificador de la contaminación, en este caso atmosférica, al menos en un supuesto, pues, en vez de hablar, como hacía la Directiva 76/464/CEE, de "perjudicar los recursos vivos y el sistema ecológico", exige la Directiva 84/360/CEE que la acción de los contaminantes "cause daños a los recursos biológicos y a los ecosistemas».

Dicho esto procede mencionar la variante que en la lista de bienes jurídicos protegidos de la contaminación, por la Directiva 76/464/CEE introduce, según se anunciaba, la Directiva 84/360/CEE cuando dice que quiere proteger a "los bienes materiales" del deterioro ocasionable en ellos por la contaminación atmosférica, ampliando así la formulación al respecto de la Directiva 76/464/CEE que nada dice de preservarlos frente a la contaminación del agua, sin que falten bienes sumergidos en ella susceptibles de dañarse cuando se contamina".

Ahora bien, con ser interesante el mencionado añadido a lista de bienes jurídicos protegidos de la contaminación acuática, para el caso en que de la contaminación atmosférica se trate, reviste mayor atractivo, en razón del objeto de estudio al que responden estas páginas, la referencia al medio ambiente que encierra la Directiva 84/360/CEE en el inciso final de su Art. 2.1. A cuyo respecto no conviene pasar por alto la posibilidad de entenderse que enuncia el propósito de incorporar un elemento nuevo al referido catálogo de bienes tutelados por la Directiva 76/464/CEE. Desde luego que el indicado precepto se aviene a inter- 
pretarse en ese sentido - por más que la Directiva 84/360/CEE no aclare en ningún sitio qué alcance le concede a la expresión "medio ambiente»-, pues la dificultad que media entonces en orden a identificar el bien en cuestión, no sería tanta de estimarse al legislador europeo en de 1984 persuadido de actuar en sintonía con la sociedad de su tiempo, esto es, de utilizar un concepto cuyo significado no ignoraba nadie y que, por tanto, resultaba ocioso definir.

Sin embargo, es obvio que la disposición ahora comentada admite una interpretación distinta, más en consonancia con la enorme semejanza que, a pesar de las diferencias reseñadas, guardan entre sí, según ha quedado dicho, el Art. 2.1.e) de la Directiva 76/464/CEE y el Art. 2.1 de la Directiva 84/360/CEE. Tan intenso es el parecido entre ambos preceptos, cabe añadir, que no se alberga aquí ninguna duda respecto a su causa u origen inmediato. Búsqueselo en haber servido el enunciado del primero, de modelo para redactar el del segundo, y adviértase cómo, observadas las referidas disposiciones desde la óptica que proporciona la intermediación de ese vínculo, nada tiene de particular la evidente similitud de sus respectivos incisos finales. Repárese en que basta considerárselos también conectados por el espíritu de la emulación, para que "otras utilizaciones legítimas de las aguas" y "otras utilizaciones legítimas del medio ambiente", se revelen expresiones dotadas de significados afines, apenas diferentes porque apelan a los respectivos sujetos pacientes de las diversas clases de contaminación a que atienden las normas indicadas. Esto es, el medio acuático o las aguas, en el caso de la Directiva 76/464/CEE y el medio atmosférico o la atmósfera, en el dela Directiva 84/360/CEE.

Tal es el sentido que se juzga más razonable asignar a la locución "otras utilizaciones legítimas del medio ambiente». Interesa subrayarlo, porque de esa interpretación es tributario el significado aquí atribuido al nexo que anuda la Directiva 84/360/CEE entre contaminación y medio ambiente al usar en el inciso final de su Art. 2.1 aquella expresión. Pues se estima que, en su virtud, el precepto vincula a la contaminación con la atmósfera o el medio atmosférico, para operar, de acuerdo con ello, como una cláusula genérica de salvaguardia, ciertamente útil, frente a la contaminación atmosférica procedente de instalaciones industriales, que, no se olvide, proporciona su objeto a la citada Directiva ${ }^{18}$.

18 De igual modo que a tantas otras normas no comunitarias de la época, cabe añadir. Recuérdese, sin ir más lejos, la atención prestada por el ordenamiento español a la contaminación atmosférica, general, y a la de origen industrial, en particular, desde antes incluso de aprobarse la Directiva 84/360/CEEE. Así lo evidencian 


\subsection{La información medioambiental en el Derecho Comunitario derivado}

Otras normas comunitarias cuya consulta ha sido provechosa para la indagación abordada en estas páginas son las que, de modo sucesivo, se han ocupado de facilitar el acceso del público a la información medioambiental. Se trata de la Directiva 90/313/CEE del Consejo, de 7 de junio de 1990, y de la Directiva 2003/4/CE del Parlamento Europeo y del Consejo, de 28 de enero de 2003, derogatoria de la anterior.

De la primera merece destacarse, en primer lugar, la rotunda afirmación de su Art. 1, destinada a especificar que el objeto de la misma era garantizar la libertad de acceso y la difusión de la información sobre el medio ambiente, en poder de las autoridades públicas y establecer los plazos y las condiciones básicas para poner a disposición de los solicitantes dicha información. Así como, en segundo lugar, el significado que asignaba a la expresión "información sobre medio ambiente», pues, según su Art. 2 había de entenderse por tal "cualquier información disponible (...) sobre el estado de las aguas, el aire, el suelo, la fauna, la flora, las tierras y los espacios naturales, y sobre las actividades (incluidas las que ocasionan molestias como el ruido) o medidas que les afecten o puedan afectarles, y sobre las actividades o medidas destinadas a protegerlos, incluidas las medidas administrativas y los programas de gestión del medio ambiente»

Desde luego que el precepto es rico en sugerencias. De entre ellas merece destacarse, por su interés para estas páginas, en primer lugar las alusiones continuas a la contaminación que encierran dichas consideraciones normativas, expresamente dedicadas a la información medioambiental. Pues como tales referencias a ese fenómeno admiten estimarse sus llamadas sucesivas al estado de los bienes que enumera, a las actividades y medidas susceptibles de afectarles negativamente, y a las actividades y medidas destinados a protegerlos.

En absoluto se opone a dicha interpretación del precepto su lacónico tratamiento de los bienes que menciona. Es más, por seguir con la

no pocas disposiciones del Reglamento de actividades molestas, insalubres, nocivas y peligrosas, aprobado por el Decreto 2414/1961, de 30 de diciembre; el Decreto 2107/1968, de 16 de agosto, sobre régimen de poblaciones con altos niveles de contaminación atmosférica o perturbaciones por ruidos y vibraciones; el Decreto 2861/1968, de 7 de noviembre, sobre medidas para evitar la contaminación atmosférica producida por partículas sólidas en suspensión en los gases vertidos al exterior por fábricas de cemento; la Ley 38/1972, de 22 de diciembre, de protección del ambiente atmosférico; y el Decreto 833/1975, de 6 de febrero que la desarrolla. 
distinción efectuada al analizar las Directivas 76/464/CEE y 84/360/CEE, cabe deducir incluso que en la disposición ahora examinada tales bienes son considerados sujetos pacientes de la contaminación certificable por sus efectos perceptibles en esos otros bienes a los que viene denominándoseles tutelados frente a la acción contaminante, sin negar por eso la incuestionable protección que también dispensa a los aquí denominados sujetos pacientes de la contaminación cualquiera de las normas analizadas hasta ahora.

Téngase en cuenta que, según todo indica, el ruido es mencionado por el Art. 2 de la Directiva 90/313/CEE en calidad de agente contaminante ${ }^{19}$ y que cómo no se alcanza a comprender de qué modo puede ocasionar éste molestias a las aguas, el aire, el suelo, la flora, las tierras y los espacios naturales, ni siquiera a lo más sensitivo, la fauna, entendiendo por tal lo que el Diccionario de la Real Academia, esto es, "el conjunto de animales de un país o región", pues muy pequeña habría de ser la superficie considerada o superlativo el ruido, forzosamente habrán de evaluarse sus propiedades contaminantes por los efectos que produzca en el ser humano, tan sensible a las molestias del ruido como para identificar la ausencia del mismo con su bienestar y convertir esta situación en un bien jurídicamente protegible.

No menos interés para estas páginas reviste el que, también en su Art. 2, aluda la Directiva 90/313/CEE, en segundo lugar a la existencia de una relación entre los bienes que menciona y el medio ambiente que no es descabellado estimar, como aquí se hace, determinada por la contaminación. En concreto, se refiere el precepto a dicho vínculo cuando, al hablar de las actividades y medidas destinadas a proteger aquellos bienes, cita expresamente "las medidas administrativas y los programas de gestión del medio ambiente».

De ordinario, se impondría consultar dichos programas en busca de datos más precisos sobre esa relación a que alude la citada disposición, sin embargo, puede renunciarse en este caso a efectuar dicha tarea, considerando la esclarecedora información que al respecto proporciona la norma más arriba referida, sucesora, por derogatoria, de la ahora comentada, esto es, la Directiva 2003/4/CEE del Parlamento Europeo y del Consejo, de 28 de mayo de 2003, relativa al acceso del público a la información medioambiental y por la que se deroga la Directiva 90/313/CEE del Consejo.

19 Para concederle así la misma consideración que con anterioridad le había dispensado el ordenamiento español en el Decreto 2107/1968, de 16 de agosto, sobre régimen de poblaciones con altos niveles de contaminación atmosférica o perturbaciones por ruidos y vibraciones. 
Téngase en cuenta que según dispone la Directiva vigente en su Art. 2.1.a), ha de entenderse por información medioambiental la relativa a "la situación de elementos del medio ambiente, como el aire y la atmósfera, el agua, el suelo, la tierra, los paisajes y espacios naturales, incluidos los humedales y las zonas marinas y costeras, la diversidad biológica y sus componentes, incluidos los organismos modificados genéticamente, y la interacción entre estos elementos".

La elocuencia del precepto sobre el heterogéneo conjunto de bienes que relaciona y no sólo porque el vínculo con la naturaleza -perceptible en la mayoría de los casos-, sea desplazado por un nexo con lo artificial, en el caso de los organismos modificados genéticamente, exime de cualquier comentario al respecto. Pero si se ha juzgado oportuno hacer constar aquí ese dato, con tanto mayor motivo se estima procedente obrar de igual modo y llamar la atención sobre otra circunstancia de interés más inmediato para estas páginas, cual es la facilidad con que se avienen a entenderse incorporados los bienes de la Directiva 90/313/CEE en este catálogo de la Directiva 2003/4/CEE. De ahí lo superfluo de las pesquisas en torno a la insinuación de la Directiva derogada sobre la existencia de una relación entre los bienes que enumeraba y el medio ambiente. Cualquiera que pudiera ser ese nexo deviene irrelevante ante la posterior evolución de los hechos, al dispensarles la Directiva en vigor la consideración de elementos medioambientales.

Ahora bien, el tenor empleado por el Art. 2.1.a) de la Directiva 2003/4/CEE impide concluir afirmando que para el legislador europeo el medio ambiente sea ese compositum de bienes, de tal modo que su idea sobre aquél se agote en estos, y no sólo porque ese tono del precepto, a fuer de puramente ejemplificativo, consiente pensar en la posible incorporación a la lista de otros bienes, sino por lo que a continuación dice la Directiva en torno a la información medioambiental. Téngase en cuenta que, según añade al respecto en su Art. 2.1.b), también ha de considerarse tal la atinente a "factores como sustancias, energía, ruido, radiaciones o residuos, incluidos los residuos radiactivos, emisiones, vertidos y otras liberaciones en el medio ambiente, que afecten o puedan afectar a los elementos del medio ambiente citados en la letra a)".

Dos veces, obsérvese, utiliza este Art. 2.1.b) la expresión medio ambiente. Para apelar con ella, en primer término, de igual forma que lo hacía el Art. 2.1 de la Directiva 84/360/CEE, según todo indica, a la atmósfera o el aire; y para referirse, en segundo lugar, a la incidencia de esas sustancias, energía, ruido, residuos y vertidos en los bienes que 
enumera la Directiva 2003/4/CE en su artículo 2.1.a). De modo que, no obstante calificar el legislador europeo a éstos últimos como elementos del medio ambiente, admite en el Art. 2.1.b) que no son los únicos componentes del mismo, al afirmar que con ellos pueden interaccionar esos a los cuales denomina factores, de incuestionables propiedades contaminantes, como así se ocupa de confirmar la Directiva algo más adelante. Pues, en efecto, pasando por alto ciertos extremos de la norma irrelevantes para estas páginas ${ }^{20}$, interesa destacar que en su Art. 2.1.f) asigna la consideración de información medioambiental a la atinente al "estado de la salud y la seguridad de las personas, incluida, en su caso, la contaminación de la cadena alimentaria, condiciones de vida humana, emplazamientos culturales y construcciones cuando se vean o puedan verse afectados por el estado de los elementos del medio ambiente citados en la letra a) o a través de esos elementos, por cualquiera de los extremos citados en las letras b) y c) " ${ }^{21}$.

Apenas se destacará de este último apartado su paralelismo con lo dispuesto en el las Directivas 76/464/CEE y 84/360/CEE sobre los bienes inmediatamente tutelados en los casos de contaminación acuática y atmosférica, respectivamente, dada la afín naturaleza de los mismos y de los incluidos en el catálogo de la Directiva 2003/4/CEE, bastante más elaborado, por cierto que cualquiera de los registrados en esas Directivas anteriores. Obsérvese si no la evolución verificada en el tratamiento de la salud humana por unas y otras normas; y no se pase por alto la diferente regulación que le han concedido tales Directivas a otro asunto: recuérdese que la Directiva 76/434/CEE apela a los posibles daños a los lugares de recreo y las molestias para otras utilizaciones legítimas de las aguas; no se olvide que la Directiva 84/360/CEE habla del eventual deterioro de los bienes materiales y el daño o perjuicio para las actividades recreativas y otras utilizaciones legítimas del medio ambiente; $y$, adviértase cómo la Directiva 2003/4/CEE se refiere a la posibilidad de verse afectados por la contaminación las condiciones de vida o los emplazamientos culturales y las construcciones.

20 Se alude a lo dispuesto en las letras c), d), y e) de ese Art. 2.1:

uc) medidas (incluidas las medidas administrativas) como políticas, normas, planes, programas, acuerdos en materia de medio ambiente y actividades que afecten o puedan afectar a los elementos y factores citados en las letras a) y b), así como las actividades o las medidas destinadas a proteger estos elementos.

«d) informes sobre la ejecución de la legislación medioambiental.

«e) análisis dela relación coste-beneficio y otros análisis y supuestos de carácter económico utilizados en el marco de las medidas y actividades citadas en la letra c)".

21 Cfr. nota anterior. 
En resumidas cuentas, a la vista de lo que el Art. 2.1 de la Directiva 2003/4/CEE considera información medioambiental no es difícil deducir que el sector de la realidad sobre el cual ha de versar la información objeto de su regulación es un fenómeno complejo en el que se dan cita diversas circunstancias, erigiéndose entre ellas en protagonista la contaminación. Pues desde luego que el legislador alberga una idea de medio ambiente inconcebible sin la de liberación en el aire o la atmósfera, el agua, el suelo, etc., de sustancias energías, ruidos, radiaciones, etc., con efectos para la salud y la seguridad de las personas, la cadena alimentaria, etc. Interesa subrayarlo y con base en ese dato llamar la atención sobre cuánto expresa de dinámico el que tales sujetos pacientes de la contaminación, esos agentes contaminantes y los referidos bienes tutelados de forma inmediata frente a dicho fenómeno, resulten ser lo más destacado del medio ambiente en la citada Directiva. Quiere decirse con ello que para el legislador europeo aisladamente consideradas ninguna de tales categorías - ni mucho menos sus componentes- definen el medio ambiente. De modo que ha de producirse la suerte de interacción entre las mismas, consustancial a la contaminación, para aprehender su significado. De donde se sigue que también desde una perspectiva jurídica, el vínculo anudable entre una cosa y sus contaminantes define al medio ambiente; o lo que es lo mismo, que en el Derecho Comunitario Europeo la contaminación y el medio ambiente son conceptos que guardan entre sí una relación tan intensa como para concluir erigiéndose el primero en fundamento conceptual del segundo. 